\title{
RELATEDNESS OF CHLORAMPHENICOL RESISTANCE PLASMIDS IN EPIDEMIOLOGICALLY UNRELATED STRAINS OF PATHOGENIC ESCHERICHIA COLI FROM MAN AND ANIMALS
}

\author{
SIGRID TUE JøRGENSEN
}

Department of Genetics, Royal Veterinary and Agricultural University, 13 Bülowsvej, 1870 Copenhagen $V$, Denmark

\begin{abstract}
SUMmaRY. I have examined 20 plasmids conferring chloramphenicol resistance $(\mathrm{Cm})$ in multiresistant strains of Escherichia coli pathogenic for man and piglets. In Denmark, one plasmid family, exemplar pHG33, is responsible for all chloramphenicol resistance in serotypes of E. coli found in diseased piglets. A closely related plasmid, pHG50, was identified in an enteropathogenic $E$. coli (EPEC) strain from an infant. The isolate was epidemiologically unrelated to the piglet isolates. The molecular relatedness of the plasmids was established by restriction enzyme analyses and Southern blots. Chloramphenicol resistance plasmids in E. coli from urinary tract infections, or in English EPEC strains, did not show the same close relatedness with the piglet plasmid pHG33. However, many were of the same incompatibility group and their restriction profiles displayed a number of common bands. The close relatedness of pHG50 and pHG33 suggests exchange of plasmids between pathogenic serotypes of $E$. coli from man and animals. The infant from whom the EPEC strain carrying plasmid pHG50 was isolated might have acquired it from piglets. Disease in human babies caused by EPEC strains is now rare in Denmark and no Cm-resistant strains are found. Possible reasons for the loss of $\mathrm{Cm}$-resistance plasmids from human strains and their retention in piglet strains are discussed.
\end{abstract}

\section{INTRODUCTION}

Several reports have shown that animals and human beings who share an environment exchange microorganisms (Lyons et al., 1980). This may happen even under experimental conditions when strict hygienic precautions are taken and may include exchange of plasmids (Levy, Fitzgerald and Macone, 1976; Hirsh and Wiger, 1977). The finding of closely related plasmids in epidemiologically unrelated bacterial strains from animals and man has rarely been described.

There are, however, data on enterobacterial plasmids from man that show a high 
degree of relatedness although the plasmids came from widely separated geographical regions (Sharp, Cohen and Davidson, 1973); degradative plasmids in bacteria from soil show the same trend (Duggleby et al., 1977). This implies that there is a worldwide distribution of particular plasmids in particular ecological niches. This view finds support in a study of relatedness among enterobacterial plasmids of the same incompatibility group (Anderson, Humphreys and Willshaw, 1975). The authors state that there are no distinctions between plasmids from man and animals except those caused by different resistance markers, implying that, irrespective of where they first happen to be seen, these plasmids are drawn from a common pool. I agree with this statement, but I have used another approach to study plasmid relatedness-restriction enzyme analysis of plasmid DNA (Causey and Brown, 1978).

It has been reported previously (Jørgensen, 1978; Jørgensen and Sørensen, 1979; Jørgensen et al., 1980b) that chloramphenicol (Cm) resistance in Escherichia coli from Danish piglets is encoded by a single plasmid with great ability to persist and spread among certain enteropathogenic serotypes. Encouraged by the debate on risks to human health by excessive use of antimicrobials in animals (National Academy of Science, 1980) my study of Cm-resistant $E$. coli in piglets was extended to include a number of $\mathrm{Cm}$-resistant human strains. Some of these were enteropathogenic E. coli (EPEC) from infants in Denmark and the United Kingdom; some were isolated from urinary tract infections in Danish adults, because it proved difficult to find $\mathrm{Cm}$-resistant EPEC strains of a more recent date in Denmark. Their Cm-resistance plasmids were characterised by the methods that were used for those from piglet pathogenic $E$. coli, and the results are reported here.

\section{MATERIALS AND METHODS}

Strains. All strains were selected because of their resistance to chloramphenicol. The strains from piglets were described in a previous publication (Jørgensen, 1978). The human strains comprised two groups: (i) 13 strains of enteropathogenic E. coli (EPEC)-five Danish strains isolated in 1964 at The State Serum Institute, Copenhagen were supplied by Dr I. Ørskov, and eight British strains isolated in 1980 and 1981 were from Dr B. Rowe, Central Public Health Laboratory, Colindale, London NW9 5HT; (ii) six strains isolated in 1977 from urinary tract infections were obtained from Dr P. Søgaard, The State Serum Institute, Regional Laboratory, Odense. The Danish strains were serotyped at The Collaborative Centre for Reference and Research on Escherichia and Klebsiella (WHO), The State Serum Institute, Copenhagen.

Conjugation and transformation experiments and compatibility testing were performed by the methods described by Jørgensen (1978) and Jørgensen et al. (1980a).

Extraction of plasmid DNA was done by the method described by Birnboim and Doly (1979), modified to use $10 \mathrm{ml}$ of starting culture. The plasmid DNA used for restriction enzyme analysis was further purified in caesium-chloride-ethidium-bromide gradients as described by Jørgensen et al. $(1980 b)$.

Restriction enzyme analysis, gel electrophoresis and hybridization experiments were as described by Jørgensen et al. (1980a); the hybridisation techniques were based on those of Southern (1975). In cases where better resolution of large fragments was necessary the agarose gels were run horizontally in a Tris-acetate-EDTA buffer $(100 \mathrm{~mm}$ Tris-acetate, $1 \mathrm{~mm}$ EDTA, $p \mathrm{H}$ 8.1). Agarose was either type HSA for conventional use or type LSL for the horizontal gels run at low voltage overnight; both were manufactured by Litex, Glostrup, Denmark. The concentration of agarose in the gels was $0.7-1 \%(\mathrm{w} / \mathrm{v})$. Restriction endonuclease EcoRI was either purchased from Boehringer-Mannheim or prepared in the laboratories in Bristol or Copenhagen from strain RY13 by a method supplied by Dr J. Ward (personal communication). Restriction endonucleases BgIII and PstI were purchased from Boehringer-Mannheim. 
Electron microscopy of plasmid DNA was performed as described by Robinson, Bennett and Richmond (1977).

Minimal inhibitory concentrations of drugs were measured in broth by the method of Ericsson and Sherris (1971).

\section{RESULTS}

The properties of the $\mathrm{Cm}$ plasmids in pathogenic $E$. coli strains from man are summarised in the table. In the last line of the table the corresponding characteristic of the porcine plasmid that was used for comparison are shown. The 11 Danish plasmids had a common core of resistance determinants - chloramphenicol, streptomycin, sulphonamide ( $\mathrm{CmSmSu}$ ) - whereas in three of the English strains the $\mathrm{SmSu}$ markers were either missing or located on another plasmid (table, columns 5 and 6). $\mathrm{Cm}$ is, therefore, the only resistance marker common to all plasmids in the survey. However, the majority of the plasmids encoded resistance to ampicillin (Ap) and tetracycline (Tc), either together or singly, and four conferred resistance to kanamycin $(\mathrm{Km})$. Seventeen of the 19 plasmids were conjugative at $37^{\circ} \mathrm{C}$ and two at $28^{\circ} \mathrm{C} ; 13$ were classified as IncFII. Their sizes were within the range $(60-80) \times 10^{6} \mathrm{~mol}$. wt as determined by restriction endonuclease analysis or by contour measurements in the electron microscope. Thus, the majority of the $\mathrm{Cm}$ plasmids had several common features despite the fact that they originated in two different countries, that they were located in strains from two disease foci - the urinary tract and the intestine - and that they had been isolated during a period of 16 years.

\section{Restriction enzyme analysis}

Plasmid DNA was isolated from four ApCmSmSu-, two ApCmSmSuTc-, four ApCmKmSmSuTc-, four CmSmSuTc-, two ApCmTc-, and one CmTc-resistant transformants and digested with restriction endonuclease EcoRI. The restriction profiles were compared with each other and with the EcoRI restriction profile of the plasmid from the piglet strain. Digestion with two other restriction enzymes, Pst $\mathrm{I}$ and $B g I I I$, was performed when the EcoRI patterns indicated identity between plasmids.

EcoRI endonuclease analysis. Plasmid pHG50, found in a Danish EPEC strain from 1964 (table), had an EcoRI restriction profile of 11 fragments (fig. 1a), eight of which were also present in plasmid pHG33, a standard type-plasmid in piglet pathogenic E. coli (table and fig. 1a). However, despite their nearly-identical EcoRI patterns the mol. wt of plasmid pHG50 is $c .13 \times 10^{6}$ greater than that of plasmid pHG33 as shown by EM measurements and by restriction enzyme analysis. A closer examination of fig. la reveals that fragments no 5, 7,9 and 11 of plasmid pHG50 are doubles. The results were confirmed in EcoRI/BgIII double digestions (data not shown).

Two indistinguishable plasmids, pHG51 and pHG54 (table), had EcoRI restriction profiles with some similarity to that of plasmid pHG33 (fig. 1a). At least six of their 14 fragments were the same size as fragments of plasmid pHG33. However, they are less closely related to pHG33 than is plasmid pHG50. This was confirmed by digestions with $B g I I I$ and PstI (data not shown). In the remaining human strains plasmids were observed that had various numbers of fragments in common with plasmid pHG33, but no more than is usually found among plasmids of the same Inc group. 
Another two sets of identical or very similar plasmids were identified by the EcoRI analysis: (i) the plasmids in two EPEC strains from Colindale, pHG61 and pHG68, were indistinguishable (fig. $1 \mathrm{~b}$ ) although they were present in strains of different antigenic type (table); (ii) two plasmids in $E$. coli strains from urinary tract infections, pHG56 and pHG57, had in common all fragments but one in their 17/18 band restriction profile (fig. 1c).

PstI restriction endonuclease analysis. Because the plasmid from piglet pathogenic E. coli, pHG33, is known to have a large number of recognition sites for restriction endonuclease Pst I, plasmid DNA from pHG33 and pHG50 was digested with Pst $\mathrm{I}$. Their restriction profiles are shown in fig. 2. With DNA of pHG33 and pHG50, PstI produced 21 and 24 fragments, respectively. Twenty of these fragments were the same sizes. Discrepancies between the restriction profiles appear in fragments nos. 1, 4, 19 and 20 of pHG50 which are missing from the pHG33 profile and in band no. 17 of pHG33 which is absent from the pHG50 profile.

BgIII restriction endonuclease analysis. The DNA from plasmids pHG51 and pHG54 had indistinguishable EcoRI restriction profiles and was subjected to digestion

TABLE

Characteristics of chloramphenicol resistant $E$. Coli strains and their Cm plasmids

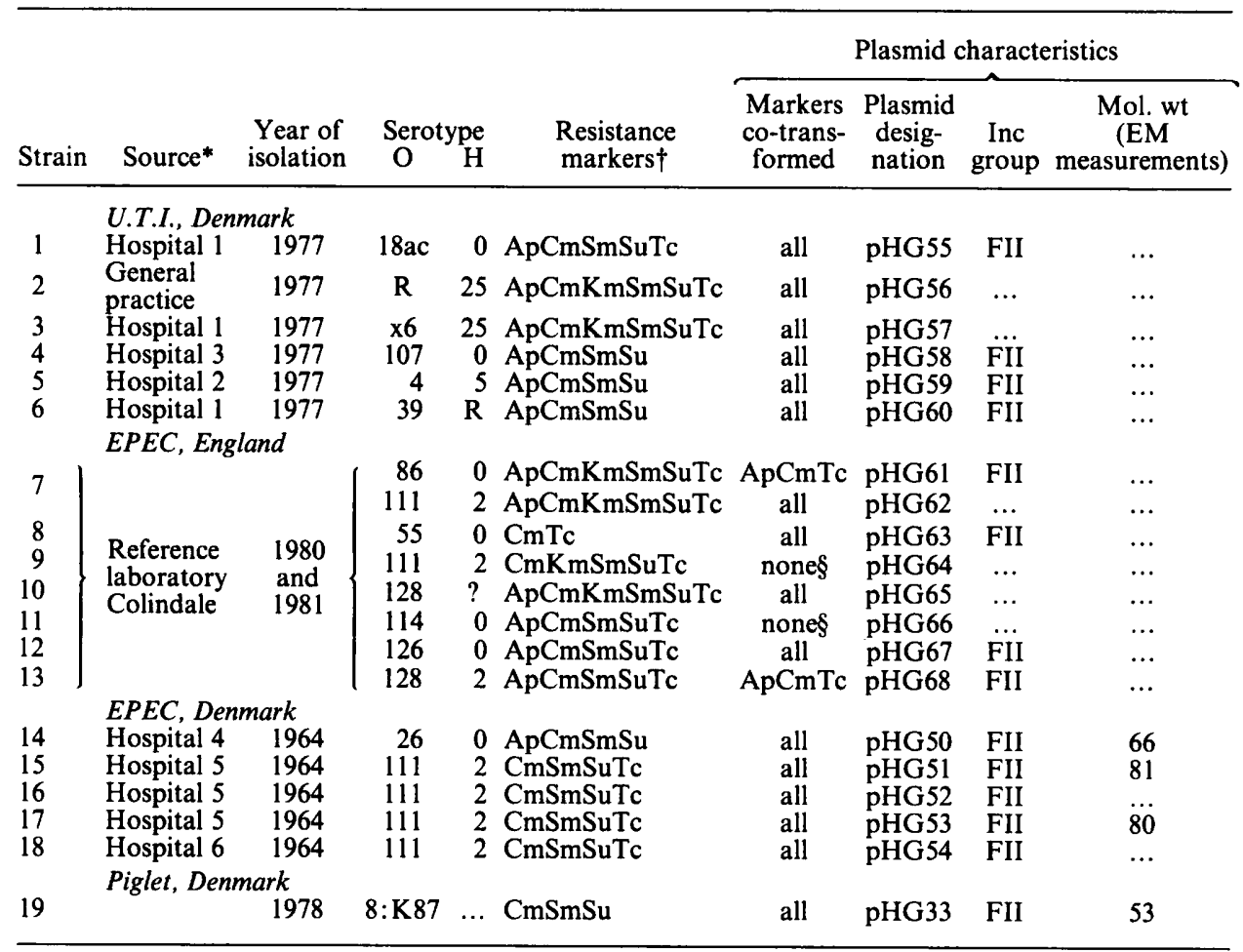

* All Danish strains from man were referred to the State Serum Institute for serotyping.

$\dagger \mathrm{Ap}=$ ampicillin, $\mathrm{Cm}=$ chloramphenicol, $\mathrm{Km}=$ kanamycin, $\mathrm{Sm}=$ streptomycin, $\mathrm{Su}=$ sulphonamides, $\mathrm{Tc}=$ tetracycline.

$\S$ none: no transformants obtained. 


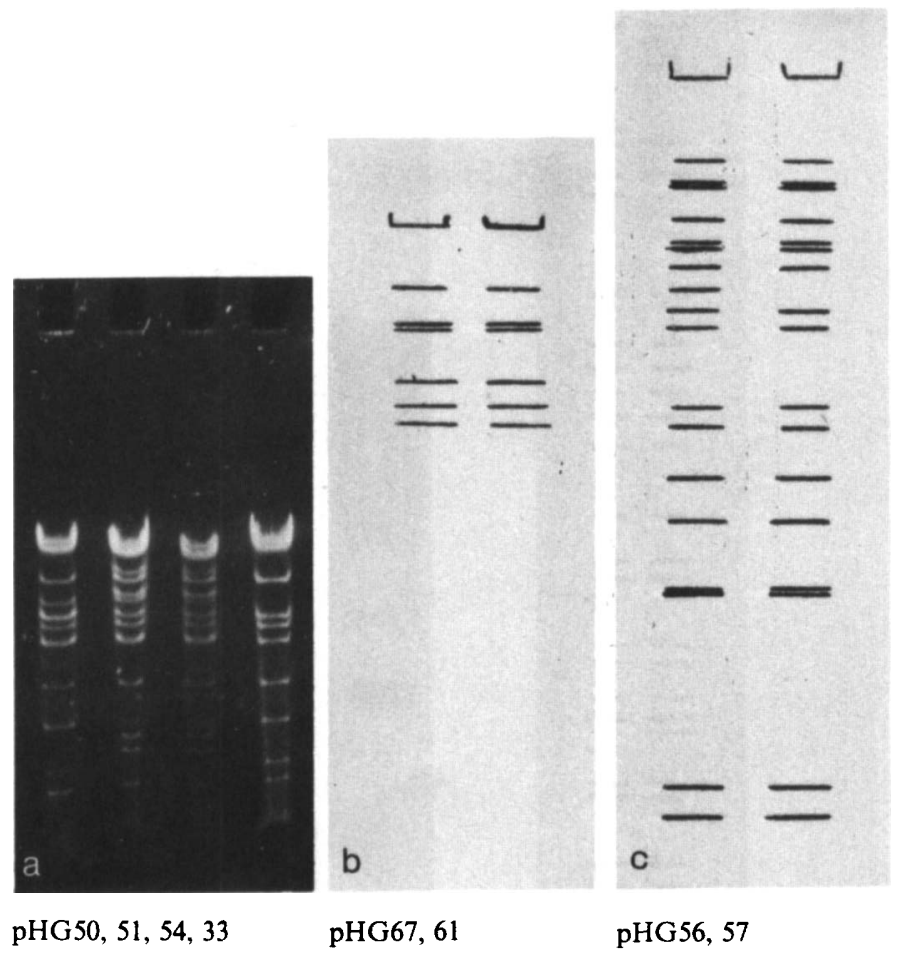

FIG. 1.-EcoRI restriction profiles of (a) plasmids pHG50, pHG51 and pHG54 from infant strains and pHG33 from the piglet strain; (b) plasmids pHG61 and pHG67 from English EPEC strains; and (c) plasmids pHG56 and pHG57 from strains of $E$. coli urinary tract infections.

with $B g$ III. Identical patterns were produced (data not shown). Corresponding results were obtained after digestion of DNA from plasmids pHG56 and pHG57 and plasmids pHG61 and pHG68, the other two sets of plasmids with indistinguishable or very similar EcoRI restriction profiles.

\section{Proof of sequence homology between plasmids pHG33 and pHG50}

Data from restriction enzyme analyses indicated an extremely close relationship between plasmids pHG33 and pHG50. This was further confirmed by hybridisation experiments. An EcoRI digest of pHG33 DNA was hybridised with a ${ }^{32} \mathrm{P}$ labelled pHG50 probe (fig. 3). It is clear that there is close homology between the two plasmids, one of which was found in an EPEC strain from man while the other is a well established plasmid in $E$. coli strains pathogenic for piglets.

\section{Determination of minimal inhibitory concentrations}

Minimal inhibitory concentrations (MICs) of chloramphenicol and streptomycin were determined for an $E$. coli $\mathrm{K} 12$ strain harbouring either $\mathrm{pHG} 50$ or $\mathrm{pHG} 33$. This was done to investigate the hypothesis that plasmid pHG50 carries a duplication of a segment of pHG33 DNA. There is a linear correlation between gene dosage and 


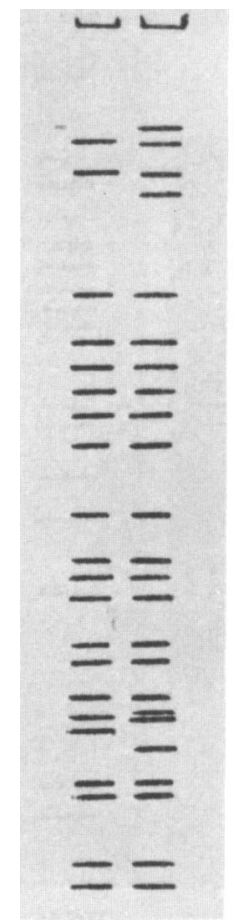

pHG33, 50

FIG. 2.

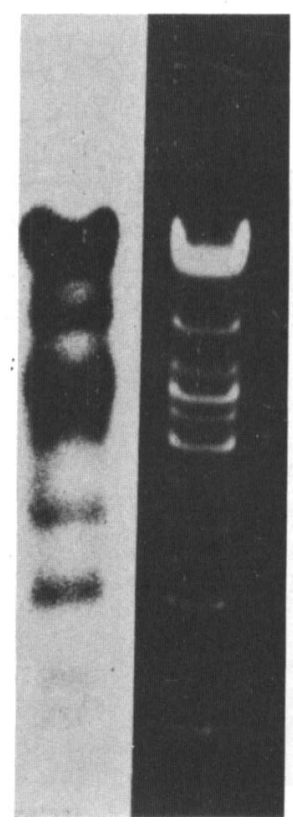

FIG. 3.

FIG. 2.-PstI restriction profile of plasmids pHG50 and pHG33.

FIG. 3.-Hybridisation of ${ }^{32}$ P-labelled pHG50 probe DNA to EcoRI-digested pHG33 DNA.

resistance level (Nordstrom et al., 1972) and the MIC should double if the duplication includes antibiotic resistance genes. The results were in accordance with this. The MIC for streptomycin was the same irrespective of which plasmid was present in the cell, but the MIC of chloramphenicol for the strain carrying pHG50 was twice that for the strain carrying pHG33.

\section{DisCUSSION}

Plasmids spread in nature in one of two ways - either with their host bacteria in a clonal mode of spread or by transfer from strain to strain; in enterobacteria plasmids are transferred most often by conjugation. Both types of spread are common in nosocomial infections (McGowan et al., 1979) where they are easily identified. Presumably similar spread occurs outside hospitals, but most often it passes unnoticed unless an epidemic starts (Crosa et al., 1977; Towner, Pearson and O'Grady, 1979).

In this survey of plasmids encoding chloramphenicol resistance in $E$. coli there were indications of both modes of dissemination (table). Plasmids pHG51 and pHG54 represent the same plasmid in one serotype. Its occurrence in two different hospitals might have been brought about by clonal spread of its host. Plasmids pHG61 and pHG68 illustrate the transfer of a plasmid between two serotypes within the same 
hospital. Finally, plasmids pHG56 and pHG57 may belong in either group. They are very closely related plasmids in different $O$ types from different environments (table and fig. 1c). At first sight their spread seems to be a case of independent plasmid transfer. However, the fact that their host strains share an uncommon $\mathrm{H}$ antigen makes it more likely that pHG56 and pHG57 have spread with their host, a clone of which has subsequently lost its $\mathrm{O}$ antigen and become rough.

The main purpose of this work was to study $\mathrm{Cm}$ plasmids in pathogenic E. coli strains from man to look for resemblance between the human plasmids and a representative of a group of already characterised $\mathrm{Cm}$ plasmids in pathogenic $E$. coli strains from piglets. In this survey of a limited number of isolates I found one example of very close relationship between such plasmids, indicating that at some stage exchange of $\mathrm{Cm}$ plasmids has taken place between $E$. coli from man and $E$. coli from animals. As already discussed by Anderson et al. (1975) the flow of plasmids is most probably bidirectional, depending on circumstances. In this particular case the infant could have acquired plasmid pHG50, but not its host, from an animal reservoir. This assumption is based on the fact that large resistance plasmids may evolve from smaller ones by accretion of resistance markers (Jørgensen et al., 1980; Jørgensen, unpublished data). Plasmid pHG50 is larger than pHG33 by c. $13 \times 10^{6}$ in mol. wt and confers additional resistance to ampicillin. Moreover, there is presumptive evidence that part of the difference in size between pHG50 and pHG33 is caused by duplication of a segment of $\mathrm{pHG} 33$ DNA including the chloramphenicol resistance genes. Alternatively, a plasmid equivalent to pHG33 might have become established in Danish EPEC strains earlier and pHG50 might subsequently have evolved therefrom.

It is interesting that plasmid pHG50, or possibly only its $\mathrm{Cm}$ genes, now seems to be absent from the population of EPEC. On the contrary, plasmid pHG33 persists in serotypes pathogenic for piglets. During recent years there have been few cases of infantile diarrhoea in Denmark, and none of the isolates show resistance to chloramphenicol (Dr I. Ørskov, personal communication). This may be because chloramphenicol is used very little in small children; on the other hand plasmid pHG50 also confers resistance to ampicillin and sulphonamides which would, therefore, be able to act as selective agents. In animals, the use of chloramphenicol was banned from 1979 onwards so, presumably, plasmid pHG33 now survives through selection of its other markers. It has not lost its $\mathrm{Cm}$-resistance genes and continues to pick up new antibiotic resistance markers (Jørgensen et al., 1980b; Jørgensen, unpublished data). Whether it possesses any other survival advantages, such as enterotoxin genes etc., is not known at present. Its host strains possess such factors, but as they harbour several plasmids the genes for pathogenicity may be located on those.

Why is plasmid pHG50 lost while pHG33 survives? One hypothesis is that the plasmid becomes established more easily in enteropathogenic or enterotoxigenic strains of human or animal origin than in strains from other disease foci. If so, plasmid pHG50 may have disappeared from humans as the EPEC strains became rare. Among piglets, however, $E$. coli infection is not unusual and the plasmid thrives. If not confirmed the hypothesis is at least not contradicted by the fact that plasmid pHG50 was absent from all the strains from urinary tract infections, although IncFII plasmids were common. Urinary tract infections are often caused by the same serotypes as populate the intestine-not by EPEC strains that rarely occur in large numbers in the healthy intestine (Ørskov and Ørskov, 1979). 
The fact that no "new" Danish EPEC strains with $\mathrm{Cm}$ resistance were available prompted me to study a few English strains. However, I did not find plasmids with any close resemblance to $\mathrm{pHG} 50$. A small pilot study with $\mathrm{Cm}$-resistant $E$. coli strains from diseased piglets in Norway (Jørgensen, unpublished data) gave no new information about plasmid pHG33. I can, therefore, conclude that pHG33 and its derivatives were able to establish themselves in particular $E$. coli serotypes of which some are known to be enterotoxigenic in piglets and another is enteropathogenic in man. There is no sign of dissemination to places outside Denmark although the plasmids spread within the country (Jørgensen et al., 1980b). Withdrawal of chloramphenicol has not yet had any demonstrable effect on the genetic constitution of the plasmid family.

I am grateful to Dr I. Ørskov, Dr B. Rowe and Dr P. Søgaard for providing strains of E. coli, to Dr J. Grinsted for restriction enzymes and to Dr J. Ward for his help with the Southern blot technique. This work was initiated while I was working at the Department of Microbiology, University of Bristol. It was supported by the Carlsberg Foundation and the Wellcome Trust. In Denmark, support was granted from the Danish Council for Scientific Policy and Planning and from the Agricultural and Veterinary Research Council, grant no. 513-20043.

\section{REFERENCES}

ANDERson, E. S., Humphreys, G. O., AND Willshaw, G. A. 1975. The molecular relatedness of $\mathrm{R}$ factors in enterobacteria of human and animal origin. Journal of General Microbiology, 91, 376-382.

BiRnboim, H. C. AND Doly, J. 1979. A rapid alkaline extraction procedure for screening recombinant plasmid DNA. Nucleic Acids Research, 7, 1513-1524.

CAusey, S. C. AND Brown, L. R. 1978. Transconjugant analysis: Limitations on the use of sequence-specific endonucleases for plasmid identification. Journal of Bacteriology, 135, 1070-1079.

Crosa, J. H., Olarte, J., Mata, L. J., Luttropp, L. K. and Penaranda, M. E. 1977. Characterization of an R-plasmid associated with ampicillin resistance in Shigella dysenteriae type 1 isolated from epidemics. Antimicrobial Agents and Chemotherapy, 11, 553-558.

Duggleby, C. J., Bayley, S. A., Worsey, M. J., Williams, P. A. ANd Broda, P. 1977. Molecular sizes and relationships of TOL plasmids in Pseudomonas. Journal of Bacteriology, 130, $1274-1280$.

ErICSSON, H. M. AND Sherris, J. C. 1971. Antibiotic sensitivity testing. Report of an international collaborative study. Acta Pathologica et Microbiologica Scandinavica, B. Suppl. 217.

HIRSCH, D. C. AND Wiger, N. 1977. Effect of tetracycline upon transfer of an R plasmid from calves to human beings. American Journal of Veterinary Research, 38, 1137-1139.

JøRGENSEN, S. T. 1978. Chloramphenicol resistance plasmids in Escherichia coli, isolated from diseased piglets. Antimicrobial Agents and Chemotherapy, 13, 710-715.

JøRGENSEN, S. T. AND SøRENSEN, V. W. 1979. Spread of an R plasmid among antigen types of Escherichia coli pathogenic for piglets. Plasmid, 2, 290-292.

Jørgensen, S. T., Oliva B., Grinsted, J. AND BennetT, P. M. 1980a. New translocation sequence mediating tetracycline resistance found in Escherichia coli, pathogenic for piglets. Antimicrobial Agents and Chemotherapy, 18, 200-205.

Jørgensen, S. T., Grinsted, J., Bennett, P. AND Richmond, M. H. 1980b. Persistence and spread of a chloramphenicol resistance-mediating plasmid in antigenic types of Escherichia coli, pathogenic for piglets. Plasmid, 4, 123-129.

Levy, S. B., Fitzgerald, G. B. AND Macone, A. B. 1976. Spread of antibiotic-resistant plasmids from chicken to chicken and from chicken to man. Nature, 260, 40-42. 
Lyons, R. W., Samples, C. L., De Silva, H. N., Ross, K. A., Julian, E. M. and Checko, P. J. 1980. An epidemic of resistant Salmonella in a nursery. Animal to human spread. Journal of the American Medical Association, 243, 546-547.

McGowan, J. E., Terry, P. M., Huang, T.-S. R., Houk C. L. ANd Davies, J. 1979. Nosocomial infections with gentamicin-resistant Staphylococcus aureus: Plasmid analysis as an epidemiologic tool. Journal of Infectious Diseases, 140, 864-872.

National ACADEMY OF SCIENCE (REPORT) 1980. The Effects on Human Health of Subtherapeutic Use of Antimicrobials in Animal Feeds, Washington DC.

NORDSTRÖM, K., INGRAM, L.C. AND LUNDBÄCK, A. 1972. Mutations in R factors of Escherichia coli causing an increased number of $\mathrm{R}$ factor copies per chromosome. Journal of Bacteriology, 110, 562.

Robinson, M. K., BennetT, P. M. AND Richmond, M. H. 1977. Inhibition of TnA translocation by TnA. Journal of Bacteriology, 129, 407-414.

Sharp, P. A., CohEN, S. N. AND DAvidson, N. 1973. Electron microscope heteroduplex studies of sequence relations among plasmids of Escherichia coli. II. Structure of drug resistance (R) factors and F factors. Journal of Molecular Biology, 75, 235-255.

SOUTHERN, E. M. 1975. Detection of specific sequences among DNA fragments separated by gel electrophoresis. Journal of Molecular Biology, 98, 503-517.

Towner, K. J., Pearson, N. J. and O'Grady, F. 1979. Resistant Vibrio cholerae el Tor in Tanzania. Lancet, 2, 147-148.

ØRSKOV F. AND ØRSKOV I. 1979. Special Escherichia coli serotypes from enteropathies in domestic animals and man. Zentralblatt für Veterinarmedizin, Suppl. 29, 7-14. 